Roy J ennings, Robert C. Read

\section{Influenza in Practice}

Royal Society of Medicine Press Ltd., London 2002 GBP 14.95

ISBN 1-85315-514-4

The book Influenza in Practice is written by two experts in infectious diseases and virology. The excellent didactic form allows a quick overview of all aspects of an influenza infection. An up-to-date summary is given of the basic data concerning virologic facts and epidemiology of influenza. In the following chapters pathogenesis and clinical assessment are discussed.

A special section outlines the risk groups of patients who urgently need an influenza vaccination. These are patients with heart disease, renal diseases, diabetes and patients who are immunocompromised.

In a separate section immunisation, antiviral drug therapy and the management of influenza infection are considered. An index allows to find any aspect of particular interest. Each chapter ends with recommendations for further reading.

On 56 pages a comprehensive overview is given of all aspects of an influenza virus infection.

The immunisation of people over 65 years of age is an indispensable part of care. It is documented that repeated annual vaccination of elderly reduces the mortality rate by an influenza infection at a range of about $75 \%$. It is proven that influenza vaccination is lifesaving, reduces hospital admissions, and modifies the severity and duration of illness. It is stressed that influenza vaccination cannot cause influenza-like symptoms.

A survey of 477 geriatricians in the UK demonstrated a general ignorance with respect to influenza vaccination: just 3\% of geriatricians recommended an influenza vaccination to their patients. $81 \%$ never used influenza vaccine, $56 \%$ regarded a vaccination as not necessary, $33 \%$ considered it as ineffective and $12 \%$ as too expensive.

No question, influenza is one of the last great uncontrolled plagues of mankind. It is a great hope that this little booklet helps to overcome the present ignorance concerning influenza vaccination, which has a remarkable impact on the life expectancy of elderly people. This book is of great importance for any postgraduate medical training, for any general physician, geriatrician, hospital physician, but also for students in undergrade and postgraduate medical education.

W. Meier-Ruge, Basel
M. Oehmichen, St. Ritz-Timme, Ch. Meissner (eds)

\section{Aging}

Morphological, Biochemical, Molecular and Social Aspects Research in Legal Medicine, vol. 27

Schmidt-Röhmhild, Lübeck 2002

EUR 90.00

ISBN 3-7950-0324-5

This book is a congress procedings volume with 6 major chapters: (1) Basic Principles of Aging, (2) Neurophysiological Aspects, (3) Protein Biochemistry in the Aging Process, (4) Molecular Biology of Aging, (5) Immunology in Aging and (6) Forensic Aspects in the Elderly. Well-known names in aging research are found such as K.A. Jellinger, H. Braak, L. Hayflick, C. Meissner, M. Oehmichen etc., to name just a few. An extended subject index helps to find any aspect of particular interest. Each article starts with a summary in English and in German.

It is hardly possible to discuss the 26 papers in detail. To mention a few highlights, it is proven that aluminium does not play a decisive role in the pathogenesis of Alzheimer's dementia.

Since Versar, collagen is a rarely considered topic in aging research. It is shown that bone collagen decreases age-dependently. No change of collagen turnover was found but a profound modification of bone collagen. Osteoporosis is characterized by an abnormal collagen metabolism which results in bone loss and further reduction in the mechanical property of the bone. In older individuals the turnover of proteoglycans is decreased, which results in a severe change in proteoglycan content. These changes lead to impaired tissue function, not only in bones but also in articular cartilage, tendons and extracellular matrix collagen.

Molecular biological findings in cell culture show that the insertion of a catalytic subunit of the telomerase gene in normal cells makes these cells immortal like cancer cells. The aging process causes a 4,977-bp deletion in mitochondrial DNA in basal ganglia, skeletal muscles and heart.

The forensic chapter deals with aspects of neglected criminal prosecution, suicides and increasing cases of homicide among elderly people.

The book offers many new data and approaches in gerontological research and makes without any doubt stimulating reading for all who work in gerontology, geriatric research, but also forensic medicine.

W. Meier-Ruge, Basel

\section{KARGER}

(C) 2003 S. Karger AG, Basel

Fax + 41613061234 E-Mail karger@karger.ch www.karger.com
Accessible online at: www.karger.com/ger 


\section{Endocrine Facets of Ageing}

Novartis Foundation Symposium 242

Wiley, London 2002

298 pp.; GBP 75.00

ISBN 0-471-48636-1

This book is a report of the Novartis Foundation's symposium on endocrine facets of ageing, which was held in London in 2001. The symposium was based on a proposal made by J.D. Veldhuis and Z. Laron. In the Chairman's introduction J.D. Veldhuis remarks that 'one aspect of research philosophy that I like is that one can identify areas of ignorance honestly: it is considered a point of brilliance to be aware of ignorance, because one can then address the corresponding issue'. The aim of the conference was fact-building and to define important aspects of ageing research that are still unresolved. Secondly, to survey many aspects of endocrinology and to discuss these with experts from different fields of research. Finally to examine 'among-axes uniformities' in ageing, as distinguished from betweenaxes differences.

The book is divided into 20 chapters and in each there is a paper followed by a summary of the discussion by the participants. The papers cover all aspects of endocrinology in relation to ageing in both the male and female where indicated. Most of the papers are very informative although a few are not for the faint-hearted. The papers on endocrine causes of age-related bone loss and ageing and water homeostasis in ageing are excellent. Where comprehensive knowledge is lacking, the authors resort to quoting papers and in some cases are reluctant to draw a conclusion from the data presented. Occasionally there is reference to data which was presented at the meeting but is not present in the text. The discussion of the papers is very good and certainly adds to the scientific background and areas of uncertainty relating to the data presented. Sometimes the discussion goes off at a tangent but perhaps this achieves one of the purposes of the conference.

I would recommend this book for specialists in the field of endocrinology of ageing or a research worker starting a career in this field to get an overview of the subject.

J. Cassar, London

\section{G.F. Hamann, M. Sieber, W. v. Scheidt}

\section{Schlaganfall}

\section{Klinik, Diagnostik, Therapie \\ ecomed, Landsberg 2002 \\ EUR 99.00 \\ ISBN 3-609-51990-8}

Stroke is a magnificent reference book about this disabling disease. 57 experts in stroke have written articles about risk factors of stroke, etiology and pathogenesis, clinic, diagnosis, therapy, prevention and rehabilitation of stroke.

The reviewer was particularly impressed by the chapter on stroke therapy. In this part of the book the most recent experience in stroke therapy is outlined. Thrombolytic therapy with tissue plaminogen activator in the first $3 \mathrm{~h}$ of the onset of stroke symptoms is recommended as treatment of choice. It provides a significant improvement in stroke symptoms. Also intra-arterial thrombolysis with prourokinase in the first $6 \mathrm{~h}$ of stroke is effective. Hemodilution is not recommended with the exception of hypovolemia.

The book gives an excellent overview of all current aspects of handling a stroke patient. All chapters are well structured. It is a particular merit of the editors to bring so many experts together for this urgently needed reference book. It is an indispensable reference for any physician in a stroke unit, a general practitioner, a neurologist or an internal specialist who is from time to time confronted with the problems of stroke. Many tables and diagrams allow a quick orientation. An extended subject index helps to find any aspect which is needed for every urgent decision in the treatment of a stroke patient.

It is a pity that this brilliant and important reference book does not exist in English, which would increase its distribution among the medical professionals remarkably. It is the hope of the reviewer that editors and publisher find a possibility to create an English version of this mangificent book.

W. Meier-Ruge, Basel 